\title{
Characterization of Clayey Soils from Congo and Physical Properties of Their Compressed Earth Blocks Reinforced with Post-Consumer Plastic Wastes
}

\author{
Raymond Gentil Elenga ${ }^{1}$, Bernard Mabiala ${ }^{1}$, Louis Ahouet ${ }^{1}$, Jean Goma-Maniongui ${ }^{1}$, Guy Francois \\ Dirras $^{2}$ \\ ${ }^{1}$ Laboratoire des Matériaux et Energies, Faculté des Sciences, Université MarienNgouabi, Brazzaville, Congo \\ ${ }^{2}$ LSPM, CNRS-UPR 3407, Université Paris 13, Villetaneuse, France \\ E-mail: ${ }^{*}$ rgelenga@gmail.com \\ Received August 16, 2011; revised September 20, 2011; accepted September 29, 2011
}

\begin{abstract}
Physical properties of compressed earth blocks reinforced with plastic wastes are compared to those of nonreinforced ones. These bricks are made with two clayey soils from two deposits of Congo located in Brazzaville and Yengola. Mineralogical and geotechnical analysis revealed that the soil of Brazzaville is mainly composed of kaolinite whereas that of Yengola is a mixture of kaolinite and illite. The amounts of clay (46 and $48 \%$, respectively) are higher than those usually recommended for bricks' production without stabilizers. Despite this difference of mineralogical compositions, the physical properties of these soils are quite similar. The compressive strength of the resulted bricks compacted with an energy of $2.8 \mathrm{MPa}$ is about $1.5 \mathrm{MPa}$, which is the lower limit value allowed for adobes. Reinforcing with polyethylene waste nets increased the strength by about $20 \%$ to $30 \%$ and slightly enhanced resistance to water, Young's modulus and strain to failure. However, the reinforcement had no significant effect either on bricks' curing length or on their shrinkage.
\end{abstract}

Keywords: Clayey Soils, Compressed Earth Block, Stabilization, Plastic Waste

\section{Introduction}

Unbaked earth bricks exist in all the continents for centuries [1]. But, the availability of starting material, the low energy consumption and the simplicity of production process justified their great usage as primary housing material in developing countries. Such constructions have good thermal comfort and sound insulation properties, but low durability $[2,3]$. Thus, during the last three decades, in central Africa for instance, the cement-based housing was preferred. The cement housing was more durable and appeared as a sign of modernity and prosperity [4].

The growing pressure from both housing shortage and the environment concern have triggered a renew interest for earth brick, chiefly because of their low environment impact $[5,6]$. In comparison with fired brick or concrete, the compressed earth blocks (CEBs) have a lower compressive strength and are less resistant to water. This high sensibility to water is a major drawback in the equatorial area.
To improve these properties without raising the costs, various local materials are used as reinforcement. Among these reinforcements, the plant fibers have the advantage of being very abundant, cheap and renewable. But, their effect on the CEB properties is variable. Indeed, they may induce a decrease of the compressive strength as already reported $[7,8]$. Such variability of the mechanical properties may be linked to: (i) the adhesion problems with the soil matrix due to the hydrophilic character of the fibers [7]; (ii) the scattering of the fiber properties themselves $[9,10]$.

On the other hand, post-consumer food-packaging polyethylene (PE) is another option for reinforcement. This product is very convenient for use, inexpensive and also very slowly degradable at room temperature (RT). Nevertheless, after its normal use, this slow degradation generates major environment concerns in developing countries. The wastes are disposed in open or uncontrolled dump. Their re-using or cheap recycling solutions are sought. Actually, in addition to their greater resistance to micro-organisms, the plastics have the advantage of 
having more reproducible properties, to be less dense than the majority of plant fibers [10] and to absorb much less water. Therefore, unlike natural fibers, plastics combine interesting properties, making them potential material for CEBs reinforcement. Indeed, Binici et al. [11] reported that the compressive strength of the CEBs is more improved by reinforcement with plastic lattice than with straw fibers. But in their work, the fibers were systematically associated with other stabilizers such as cement, lime and gypsum. Kumar et al. [12] investigated the reinforcement with polyester fibers with triangular cross-section in a highly compressive clay. The authors reported an increase of the compressive strength of about $115 \%$ in the case of $12 \mathrm{~mm}$ long fibers. Cai et al. [13] reported that the reinforcement with polypropylene fibers improves the strength of clayey soil stabilized with lime. Further, Akbulut et al. [14] showed that the reinforcement of a clayey soil with polyethylene fibers significantly enhances its geotechnical properties. None of these studies report the effect of the incorporation of plastics fibers on the resistance to water and shrinkage of CEBs.

Before the economic considerations, it is the geotechnical characteristics of the soil that determine the choice of the stabilizer. Therefore, in this study we first examine the mineralogical and geotechnical characteristics of soils used by traditional brick makers of two locations in Congo. Then, we examine the effect of introducing layers of waste PE films or nets on the mechanical properties, shrinkage and water resistance of CEBs.

\section{Materials and Methods}

\subsection{Soils}

The soils used for the manufacturing of bricks, were collected from two deposits exploited by traditional potters and brick makers. They are respectively located at Brazzaville and Yengola in Congo Brazzaville. The quarry depth varied from 1 to $2 \mathrm{~m}$.

The grading curves of the soils were carried out through both sieving and sedimentation methods, according to the standards NF P94-056 and NF P94-057. To determine the plasticity of these soils, the Atterberg limits were measured according to the standard NF P 94-051. The optimum moisture content for the manufacturing of bricks was measured with the modified Proctor test in accordance with standard NF P94-093. The qualitative determination of the mineral composition in major elements of the raw soils was performed by X-rays diffraction (XRD), differential thermal analysis and thermogravimetric analysis (DTA-TGA). The diffractograms were carried out from $10^{\circ}$ to $100^{\circ}$ in $2 \theta$ mode using an automated InelTM diffractometer equipped with a four-circle goniometer, a linear detector Inel CPS 590 with a resolution of $0.015^{\circ}$ and a monochromatic radiation of wavelength $1.7902 \AA$. The DTA-TGA tests were carried out with a Labsys SETARAM apparatus, under nitrogen and at the heating rate of $10^{\circ} \mathrm{C} \mathrm{min}^{-1}$.

\subsection{PE Net and Film Reinforcements}

The PE net used was a post-consumer onions packaging. Its wire had a diameter of about $1 \mathrm{~mm}$ and its mesh was approximately $20 \mathrm{~mm}$ side. Slides of $95 \mathrm{~mm}$ in diameter were cut out in the net. At one third and two third of the CEB length a net slide was placed. The slide diameter was chosen to avoid the net to appear on the lateral surface of the brick after the compaction.

The PE film reinforcement was a popular used bag packaging, $50 \mu \mathrm{m}$ thick. Circular holes of $10 \mathrm{~mm}$ in diameter were made within the film to avoid the CEB to be completely cut apart. The distance between two nearby holes was $2 \mathrm{~cm}$. As in the case of the net, two slides of $95 \mathrm{~cm}$ in diameter were cut out in film and incorporated at one third and two third of the CEB length.

The masses of the net and of the film slides were in average $0.7 \mathrm{~g}$ and $0.3 \mathrm{~g}$, respectively.

\subsection{The Compressed Earth Blocks}

Bricks were made by two methods: a Universal IGM press and a Proctor mould in accordance with the standard NF P 94-093. The Universal Press was used to have energy of compaction equal to that of most mechanical presses in use $(6 \mathrm{MPa})$. The dimensions of bricks made with the press were $\varnothing \times \mathrm{L}=5 \mathrm{~cm} \times 10 \mathrm{~cm}$ for those intended for the compression test and $\mathrm{L} \times 1 \times \mathrm{h}=16 \mathrm{~cm} \times$ $4 \mathrm{~cm} \times 4 \mathrm{~cm}$ for those intended for the flexural one.

Some CEBs were manufactured in a Proctor mould to stay as close as possible to the method used by the traditional brick-makers and to be able to use the same energy of compaction for all CEBs (2.8 MPa). Their dimensions were $\varnothing \times \mathrm{L}=10 \mathrm{~cm} \times 11.5 \mathrm{~cm}$. All the CEBs were dried at room temperature $\left(\approx 25^{\circ} \mathrm{C}\right)$ and in the shade.

\subsection{Physical Tests}

After three, seven, forty and twenty-eight days of drying, the compression and the flexion tests of CEBs were conducted at room temperature (RT) on an Universal IGM press with computerized acquisition. The strain rate was $6 \times 10^{-4} \mathrm{~s}^{-1}$. The influence of the polyethylene reinforcements on the drying duration was evaluated by monitoring the evolution of the CEB mass.

To take into account the shrinkage in the three dimensions, the shrinkage $S_{r}$ computed as a volume contraction was given through: 


$$
S_{r}=\frac{\left(V-V_{d}\right)}{\left(V_{w}-V_{d}\right)}
$$

$V_{w}$ and $V_{d}$ are the volumes of wetted and dried CEB, respectively.

The resistance to water of the CEB was measured according to the protocol suggested by Mbumbia et al. [15], which is a variant of the drip test. To simulate the action of rain, the surface of the block formed an angle of $63.5^{\circ}$ with the water jet. Each sample was left under the jet flow during $15 \mathrm{~min}$. The soil pulled out during the water jet exposition was collected in a container, dried in an oven and then weighed.

For each type of CEB (without reinforcement, reinforced with net, reinforced with film), each of the abovementioned tests are repeated five times.

\section{Results and Discussion}

\subsection{Geotechnical Characteristics and Mineral Composition of the Soils}

The grading curves of the soils are reported on Figure 1 and their contents in sand, silt and clay as well as the Atterberg limits and the Proctor test results are listed in Table 1. The grain size distributions of the two soils are

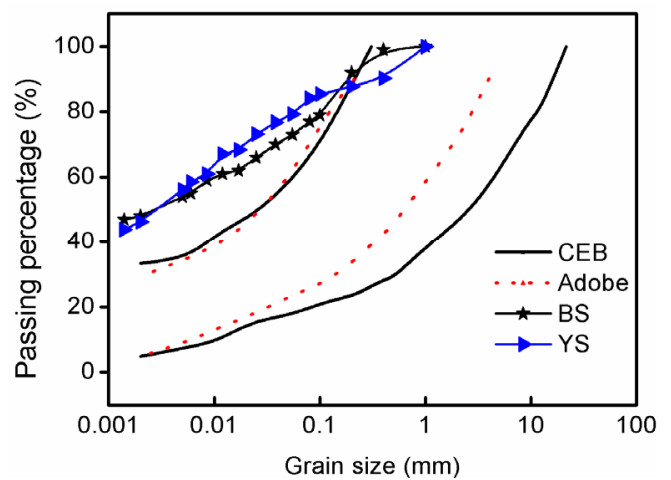

Figure 1. Grading grain size curves of the two soils compared to the standards grading curves for CEB and adobe.

Table 1. Geotechnical characteristics of the crude soils used.

\begin{tabular}{lcc}
\hline & \multicolumn{2}{c}{ Soils } \\
\cline { 2 - 3 } Parameters & Brazzaville & Yengola \\
\hline Liquid limit (\%) & 48.4 & 62.93 \\
Plastic limit (\%) & 23.2 & 24.74 \\
Plasticity index (\%) & 25.2 & 38.16 \\
Maximum dry density (g/cm3) & 1.86 & 1.94 \\
Optimum moisture content (\%) & 16.6 & 18.8 \\
Sand (\%) & 36 & 30 \\
Silt (\%) & 16 & 24 \\
Clay (\%) & 48 & 46 \\
\hline
\end{tabular}

very similar and spread out which should ease compaction. For all soils, the maximum grain size is lower than the maximum size specified in the literature. Below 0.2 $\mathrm{mm}$ their grading curves are above the recommended levels. The clay contents of Brazzaville's soil (BS) and Yengola's soil (YS) are $46 \%$ and $48 \%$, respectively. These contents are higher than those recommended for CEBs in the literature [16]. According to standards based on results of Proctor test, these soils are prohibited for CEBs and adobes [17]. Contrariwise, following standards based on Atterberg limits, the BS has optimum molding properties and should be suitable for adobe, CEBs and pottery $[16,18]$. The latter consideration illustrates that the recommendations reported in the literature for the various geotechnical parameters are not always coherent. Besides, it should be noticed that the raw BS and YS are not suitable for cement stabilization because their plastic indexes are too high [19]. Among the usual stabilizers, only the lime could be used for these raw soils. But as it is already mentioned by Bell [20], for such clay contents, important quantities of lime are required. To stabilize them with cement, addition of sand and/or a preliminary mixture with the lime are necessary. This necessary stage is a supplementary work for the manufacturers, and increases costs.

The diffractograms of these untreated and randomly oriented soils are reported on Figure 2. They show, while the BS is mainly composed of kaolinite, the YS is a mixture of illite and kaolinite [21,22]. This composition is confirmed by the DTA-TGA patterns displayed in Figure 3. It is observed that the BS peaks are at $91^{\circ} \mathrm{C}, 340^{\circ} \mathrm{C}$, $548^{\circ} \mathrm{C}$ and $952^{\circ} \mathrm{C}$. These peaks are ascribed to the interstitial water evaporation, the decomposition of goethite and organic matter, the transformation of kaolinite in

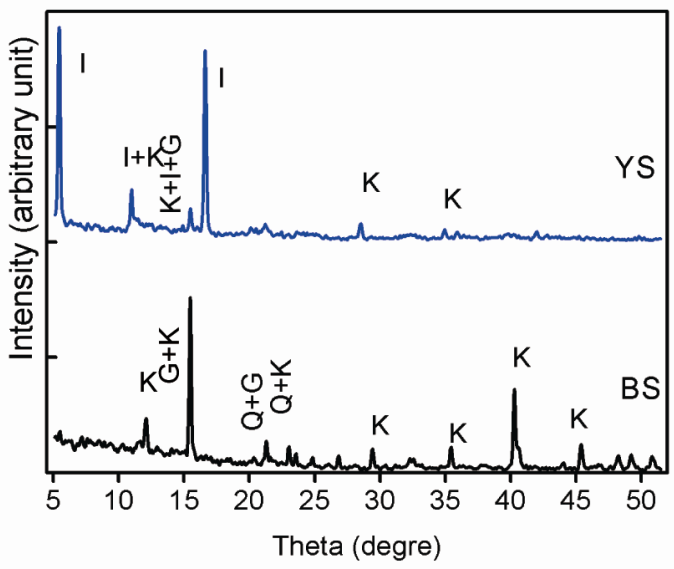

Figure 2. The DRX pattern of the crude soils used showing the Bragg peaks of the major mineral elements. $K=$ Kaolin-

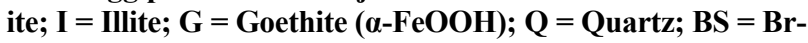
azzaville soil; YS = Yengola soil. 

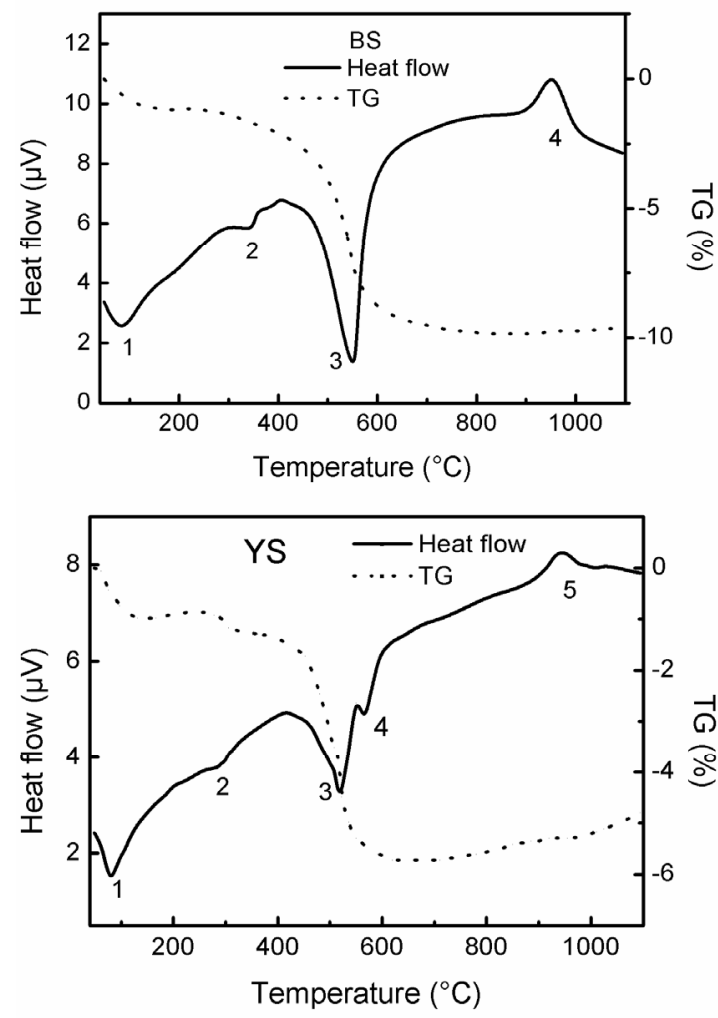

Figure 3. Thermal analysis of the crude soils exhibiting characteristic endothermic and exothermic peaks of clays: 1) Dehydratation; 2) decomposition of goethite and organic matter; 3) Kaolinite dehydroxlation; 3) Illite dehydroxylation; 4) restructuration of metakolinite.

metakaolinite and to the reorganization of metakaolinite, respectively $[22,23]$. For the $\mathrm{YS}$, there are peaks at $94^{\circ} \mathrm{C}$, $320^{\circ} \mathrm{C}, 525^{\circ} \mathrm{C}, 571^{\circ} \mathrm{C}$ and $944^{\circ} \mathrm{C}$. In this case, the peaks are attributed to the following: the dehydration, the decomposition of goethite, the formation of the metakaolinite, the allotropic transformation of the quartz and/or the structural water loss in illite, and the reorganization of the metakaolinite, respectively. Moreover, the presence of illite in YS at least partly explains why this soil has a plasticity index and optimum moisture content higher than those of BS although both soils have almost the same clay content. Assuming a mass loss of $14 \%$ for pure crystallized kaolinite, the kaolinite content of $\mathrm{BS}$ is about $62 \%[22,24]$. The mass loss of YS at $525^{\circ} \mathrm{C}$ is only about $1.65 \%$ while the BS one is $7.8 \%$, suggesting that the kaolinite content in YS is lower.

\subsection{Physical Aspect and Mechanical Resistance}

Although the soils have high clay content, none of their CEB presented visible cracks after drying. The values of the compressive strength are reported in Figure $\mathbf{4}$ for the
CEBs made with the press, and in Table 2 for those made with the Proctor mould. CEBs reinforced with the PE film often break in the plan of the film as long as they are not very dry. Thus, their average compressive strength is lower than that of non reinforced ones until the $28^{\text {th }}$ day.

The introduction of layers of PE net increases the compressive strength of CEBs for both soils and compaction
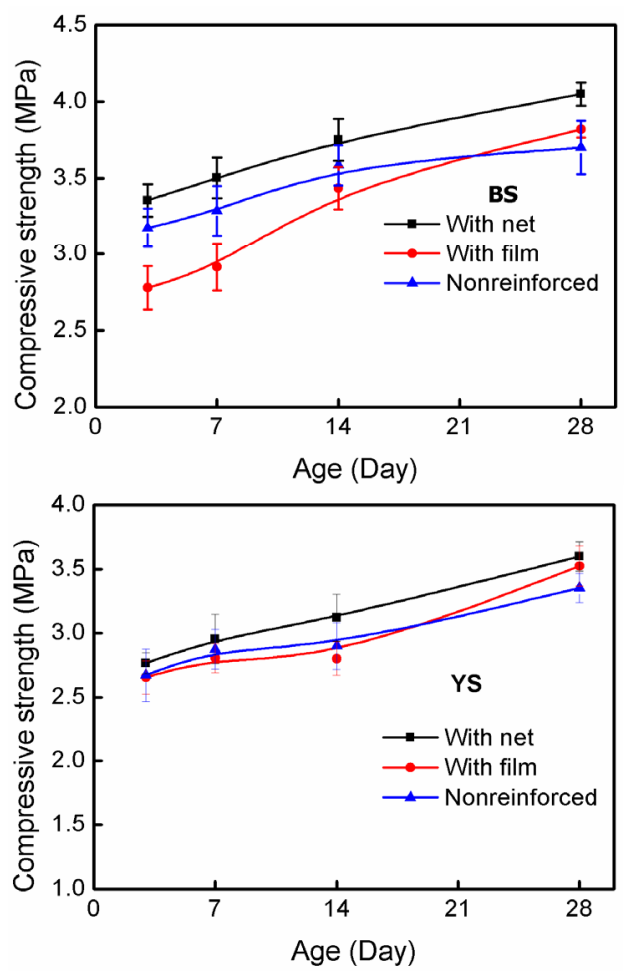

Figure 4. Variation of the compressive strength with the time and the reinforcement of the CEBs made with the press of $6 \mathrm{MPa}$.

Table 2. Effect of the reinforcement on the compressive strength and the Young modulus, the compressive strength, the elongation at failure, the volume shrinkage and the erodibility of CEBs.

\begin{tabular}{ccccc}
\hline \multirow{2}{*}{ Characteristic } & \multicolumn{3}{c}{ Reinforcement } \\
\cline { 2 - 5 } & Soil & Without & PE film & PE net \\
\hline \multirow{2}{*}{ Y. modulus (MPa) } & YS & $380 \pm 30$ & $440 \pm 20$ & $490 \pm 25$ \\
& BS & $350 \pm 25$ & $480 \pm 30$ & $560 \pm 35$ \\
Strength (Proctor MPa) & YS & $1.5 \pm 0.1$ & $1.9 \pm 0.1$ & $2.0 \pm 0.1$ \\
& BS & $1.6 \pm 0.1$ & $1.9 \pm 0.1$ & $2.1 \pm 0.2$ \\
Elongation (\%) & YS & 1.7 & 2.5 & 2.8 \\
& BS & 1.8 & 2.4 & 2.7 \\
Shrinkage (\%) & YS & $11.5 \pm 0.4$ & $10.8 \pm 0.2$ & $10.7 \pm 0.5$ \\
& BS & $7.1 \pm 0.3$ & $6.5 \pm 0.4$ & $6.8 \pm 0.3$ \\
Soil loss (\%) & YS & $12 \pm 0.7$ & $7.5 \pm 0.4$ & $7.5 \pm 0.5$ \\
& BS & $10 \pm 0.6$ & $8 \pm 0.5$ & $8 \pm 0.4$ \\
\hline
\end{tabular}


energies used here, in line with the results obtained by Binici and al. [11]. At $28^{\text {th }}$ day the compressive strengths of the blocks compressed with the press are about 3.6 MPa and 4.0 MPa for YS and BS, respectively. These values are above the minimal value $(2 \mathrm{MPa})$ required for the majority of standards [16].

Nevertheless, it should be noticed that the values of the compressive strength obtained here are about two times lower than those obtained by Binici et al [11]. This difference could be explained by several factors, especially by the addition of cement, lime and gypsum in their study. The compressive strength of the bricks made with the Proctor test is about $2 \mathrm{MPa}$. This value is above the minimal value required for adobe (1.2 $\mathrm{MPa})$ by the standards [16]. Compared to nonreinforced CEB, the increase in compressive strength is about $10 \%$ for the bricks made with the press, while it is in the range $20 \%$ $30 \%$ for the bricks made with the Proctor technique. This increase could be explained by friction forces between the reinforcement and soil during the lateral extension of the brick. Indeed, Cai et al. revealed by SEM observations that scratches appear on the fibers during deformation [13]. Compared to randomly oriented fibers, the structure of the net should create supplementary points of mechanical anchoring with the soil $[25,26]$. The increase in compressive obtained here is of the same magnitude as that obtained with vegetable fibers by Ghavami et al. [7]. However, it is lower than the one obtained by Kumar et $a l$. with polyester fiber with triangular cross-section [12].

It should be noticed that the PE net reinforcement content used is very weak, about $0.03 \%$, compared to those reported in the literature for randomly oriented vegetable fibers (ranged between $1 \%$ and $4 \%$ ) [6,7] and to that of polyester fibers in ref. [12] $(0.5 \%$ and $2 \%)$. Moreover, for small fiber contents, Kumar et al. reported that the strength increases with the increase of fiber content. Therefore, referring to the mass fraction of reinforcement, the increase of compressive strength obtained here is much greater than what is provided by plant or polyester fibers. Besides, Bahar et al. have studied the performance of CEBs stabilized with cement [27]. The compressive strength of their bricks without cement $(1.5 \mathrm{MPa})$ is the same as ours. The values of the compressive strength of PE reinforced CEBs made with the proctor technique obtained are equivalent to those they obtain with $4 \%$ cement.

The flexural strength of the CEBs is reported on the Figure 5. It increases for all reinforcements for about $8 \%$ - $10 \%$. This evolution is similar to that of the compressive strength as already reported by Morel et al. [28]. The values of the Young modulus and the elongation to failure are reported in the Table 2. They show that the introduction of the reinforcements increases the stiffness as well as the strain to failure.

\subsection{Drying Kinetics and Shrinkage}

Figure 6 shows the evolution of the CEB mass versus the time during the CEB drying. It turns out from this curve that the incorporation of layers of net or film does not influence significantly the drying duration, even if the moisture contents of CEB with reinforcement are slightly higher than those of non-reinforced bricks. The water quantity retained by YS CEB is slightly higher than
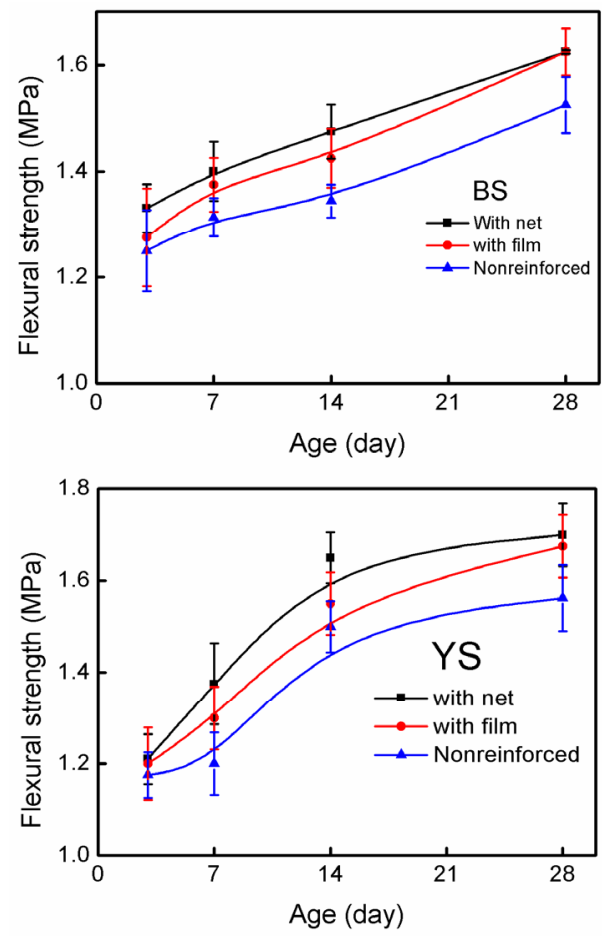

Figure 5. Variation of the flexural strength with the time and the reinforcement of the CEBs made with the press of 6 MPa.

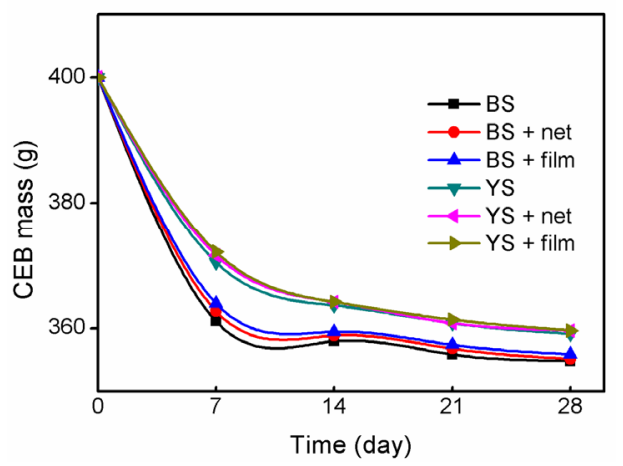

Figure 6. Effect of the reinforcement on the drying kinetics of CEBs. 
that of BS. This difference could be explained with the presence of illite in the YS. Indeed, illite is more absorbent than kaolinite.

The rates of shrinkage of the CEBs are reported in Table 2. The presence of illite in the YS may explain the highest shrinkage rate of its CEBs. Besides, it can be seen that the introduction of PE layers does not influence much the shrinkage during drying. This result seems inconsistent with that obtained by Cai et al. who observed an increase in the shrinkage rate with increasing fiber content [13]. This difference could result from the fact that they used for all fiber contents the same water content $(16 \%)$. Thus, with increasing fiber content there is more water available for the soil because the polyethylene fibers are not very absorbent. This result seems also contradictory to the increase in compressive strength reported above. A possible explanation is that during the compression process the plastic layer is under tension due to the Poisson dilation of the brick as mentioned above, and thus it opposes its resistance to the deformation with the Young modulus of about 0.5 - $1 \mathrm{GPa}$. Contrariwise, during the contraction process of the CEB, the layer is under compression in its plane, where its resistance is much lower.

\subsection{Resistance to Water}

The average rates of soil extracted from CEBs after 15 min of spraying are shown in Table 2. This test showed that reinforced CEB is slightly less eroded than nonreinforced ones. On the surface of the reinforced CEB, it forms the kind of pad around the reinforcement layers which decelerate water. In addition, between reinforcement layers hollows are formed which may impact subsequent behavior. Therefore, direct exposure of such bricks in rainy zones should be excluded.

\section{Conclusions}

In this study, geotechnical and mineralogical characteristics of two types of soils are analyzed and the mechanical properties of polyethylene reinforced CEBs made from these soils are investigated. It is found that:

(i) Soils of Brazzaville and Yengola used by traditional potters and brick-makers have similar texture but differentiate by their mineral composition. The soil of Yengola is a mixture of illite and kaolinite whereas that of Brazzaville is composed only of kaolinite. The clay contents of these soils are higher than those recommended in the literature for manufacturing CEBs and stabilization with cement.

(ii) Despite this difference of mineralogical compositions, the physical properties of these sols are quite simi- lar.

(iii) At $28^{\text {th }}$ day, the compressive strength of the nonreinforced CEBs manufactured according to the Proctor test protocol is in average $1.5 \mathrm{MPa}$. This value is within the minimal values recommended for the adobes and those for the CEBs. For nonreinforced CEBs made with the press, the compressive strength is $3.4 \mathrm{MPa}$ for Yengola soil CEBs and 3.7 MPa for Brazzaville soil CEBs.

(iv) The incorporation of the polyethylene waste (film or net) reinforcements improves slightly the resistance to water, the Young's modulus, the elongation at the failure, the compressive strength in the range of $20 \%$ to $30 \%$, the flexural strength of about $10 \%$, but does not reduce the shrinkage and the drying duration.

(v) The reinforcement with the PE net is more effective than with the PE film.

(vi) During erosion test, defects are formed. Their presence forbids a direct exposure of such bricks in rainy zones.

\section{Acknowledgements}

The authors are grateful to T. Chauveau of LSPM at university of Paris 13 and "Le Bureau de Contrôle du Bâtiment et des Travaux Publics" (BCBTP) at Brazzaville for XRD investigations and geotechnical tests, respectively. This work was carried as part of a collaborative project supported by "IFR Matériaux" at university of Paris 13.

\section{References}

[1] K. A. Heathcote, "Durability of Earthwall Buildings," Construction and Building Materials, Vol. 9, No. 3, 1995, pp. 185-189. doi:10.1016/0950-0618(95)00035-E

[2] M. L. Parra-Saldivar and W. Batty, "Thermal Behaviour of Adobe Constructions," Building and Environment, Vol. 41, No. 12, 2006, pp. 1892-1904. doi:10.1016/j.buildenv.2005.07.021

[3] J. Pineda-Piñón, J. T. Vega-Durán, A. Manzano-Ramírez, J. F. Pérez-Robles, H. Balmori-Ramírez and M. A. Hernández-Landaverde, "Enhancement of Mechanical and Hydrophobic Properties of Adobes for Building Industry by the Addition of Polymeric Agents," Building and Environment, Vol. 42, No. 2, 2007, pp. 877-883.

[4] K. Hadjri, M. Osmani, B. Baiche and C. Chifunda, "Attitude towards Earth Building for Zambian Housing Provision," Proceeding of the Institutions of Civil Engineers: Engineering Sustainability, Vol. 160, No. ES3, 2007, pp. 141-149. doi:10.1680/ensu.2007.160.3.141

[5] M. C. J. Delgado and I. C. Guerrero, "Earth Building in Spain," Construction and Building Materials, Vol. 20, No. 9, 2006, pp. 679-690. doi:10.1016/j.conbuildmat.2005.02.006

[6] J. E. Oti, J. M. Kinuthia and J. Bai, "Engineering Proper- 
ties of Unfired Clay Masonry Bricks," Engineering Geology, Vol. 107, No. 3-4, 2009, pp. 130-139.

doi:10.1016/j.enggeo.2009.05.002

[7] K. Ghavami, R.D. Toledo-Filho and N. P. Barbosa, "Behaviour of Composite Soil Reinforced with Natural Fibres," Cement and Concrete Composites, Vol. 21, No.1, 1999, pp. 39-48. doi:10.1016/S0958-9465(98)00033-X

[8] S. Yetgin, Ö. Ö. ÇAvdar and A. Çavdar, "The Effects of the Fiber Contents on the Mechanic Properties of the Adobes," Construction and Building Materials, Vol. 22, No. 3, 2008, pp. 222-227. doi:10.1016/j.conbuildmat.2006.08.022

[9] J. Andersons, E. Sparnins, R. Joffe and L. Wallstrom, "Strength Distribution of Elementary Flax Fibers," Composites Science and Technology, Vol. 65, No. 3-4, 2005, pp. 693-702. doi:10.1016/j.compscitech.2004.10.001

[10] R. G. Elenga, G. F. Dirras, J. Goma Maniongui, P. Djemia and M. P. Biget, "On the Microstructure and Physical Properties of Untreated Raffia Textilis Fiber," Composites Part A: Applied Science and Manufacturing, Vol. 40, No. 4, 2009, pp. 418-422. doi.org/10.1016/j.compositesa.2009.01.001

[11] H. Binici, O. Aksogan and T. Shah, "Investigation of Reinforced Mud Brick as Building Material," Construction and Building Materials, Vol. 19, No. 4, 2005, pp. 313-318. doi:10.1016/j.conbuildmat.2004.07.013

[12] A. Kumar, B. S. Walia and J. Mohan, "Compressive Strength of Fiber Reinforced Highly Compressible Clay," Construction and Building Materials, Vol. 20, No. 10, 2006, pp. 1063-1068.

[13] Y. Cai, B. Shi, C. W. W. Ng and C. S. Tang, "Effect Of Polypropylene Fibre and Lime Admixture on Engineering Properties Of Clayey Soil," Engineering Geology, Vol. 87, No. 3-4, 2006, pp. 230-240.

[14] S. Akbulut, S. Arasan and E. Kalkan, "Modification of Clayey Soils Using Scrap Tire Rubber and Synthetic Fibers," Applied Clay Science, Vol. 38, No. 1-2, 2007, pp. 23-32. doi: 10.1016/j.clay.2007.02.001

[15] L. Mbumbia, A. Mertens de Wilmars and J. Tirlocq, "Performance Characteristics of Lateritic Soil Bricks Fired at Low Temperatures: a Case Study of Cameroon," Construction and Building Materials, Vol. 14, No. 3, 2000, pp. 121-131. doi:10.1016/S0950-0618(00)00024-6

[16] M. C. J. Delgado and I. C. Guerrero, "The Selection of Soils for Unstabilised Earth Building: a Normative Review," Construction and Building Materials, Vol. 21, No. 2, 2007, pp. 237-251. doi: 10.1016/j.conbuildmat.2005.08.006

[17] H. Houben and H. Guillaud, "Earth Construction: A Comprehensive Guide," Intermediate Technology Publications, London, 1994, p. 362.

[18] J. A. Bain and D. E. Highly, "Regional Appraisal of Clay Resources Challenge to the Clay Mineralogist," International Clay Conference, Elsevier, Amsterdam, 1978, pp. 437-446.

[19] J. P. Walker, "Strength, Durability and Shrinkage Characteristics of Cement Stabilised Soil Blocks," Cemenf \& Concrete Composites, Vol. 17, No. 4, 1995, pp. 301-310. doi:10.1016/0958-9465(95)00019-9

[20] F. G. Bell, "Lime Stabilization of Clay Minerals and Soils," Engineering Geology, Vol. 42, No. 4, 1996, pp. 223-237. doi:10.1016/0013-7952(96)00028-2

[21] G. W. Brindley and G. Brown, "Crystal Structures of Clay Minerals and Their X-Ray Identification," Mineralogical Society Edition, London, Mongraph 5, 1980, p. 495.

[22] S. Caillère, S. Hénin and M.Rautureau, "Minéralogie des Argiles. Structure et Propriétés Physico-Chimiques," Masson, Paris, 1982, pp. 184.

[23] D. Yeskis, A. F. K. Groos and S. Guggenheim, "The Dehydroxylation of Kaolinite,"American Mineralogist, Vol. 70, No. 1-2, 1985, pp. 159-164.

[24] J. A. Bain and D. J. Morgan, "The Role of Thermal Analysis in the Evaluation of Impure Clay Deposits as Mineral Raw Materials," Clay Minerals, Vol. 8, No. 2, 1969, pp. 171-192.

[25] A. Peled and A. Bentur, "Fabric Structure and its Reinforcing Efficiency in Textile Reinforced Cement Composites," Composites Part A: Applied Science and Manufacturing, Vol. 34, No. 2, 2003, pp. 107-118. doi:10.1016/S1359-835X(03)00003-4

[26] A. Peled and A. Bentur, "Characteristics and Efficiency of Textile Fabrics for Reinforcing Cement Composites", Cement and Concrete Research, Vol. 30, No. 5, 2000, pp. 781-790. doi:10.1016/S0008-8846(00)00239-8

[27] R. Bahar, M. Benazzoug and S. Kenai, "Performance of Compacted Cement-Stabilised Soil," Cemenf \& Concrete Composites, Vol. 26, No. 7, 2004, pp. 811-820.

[28] J. C. Morel, A. Pkla and P. Walker, "Compressive Strength Testing of Compressed Earth Blocks," Construction and Building Materials, Vol. 21, No. 2, 2007, pp. 303309. doi:10.1016/j.conbuildmat.2005.08.021 